\title{
Is the Library's Online Orientation Program Effective with English Language Learners?
}

\author{
Frans Albarillo*
}

In this paper, the author examines four years of assessment data $(\mathrm{N}=4,786)$ from Brooklyn College's Library Online Orientation Program (LOOP; url: https://library.brooklyn.cuny.edu/resources/loop/loop.php), which is used to provide all English 1010 students with an orientation to the library, to see if English language learners (ELLs) are performing as well as their non-ELL peers. This paper also reports on how useful the LOOP is to ELLs when compared to non-ELLs. By comparing data from ELL and non-ELL students using several independent samples T-tests, this paper shows that ELLs on the average scored lower on the quiz component of the LOOP than non-ELLs, though they found the LOOP tutorial more useful. In addition to reporting these assessment results, this paper includes a review of the different kinds of English language learners, discusses how to statistically operationalize this population for further quantitative studies for other libraries who would like to include these additional independent variables in their assessment data collection, and provides suggestions for making the LOOP more useful to ELL students in the future.

\section{Introduction}

Helping English language learners (ELLs) access the library is an important part of reference services. This is especially true in areas with high immigrant populations. Although we have a straightforward label-English language learners - to assign to this population, understanding the information literacy needs of these students is a complex social science task. In this paper, the author studies ELLs based on how well they do on the Library Online Tutorial Program (LOOP), an online library tutorial that Brooklyn College Library, in partnership with the English department, requires all freshmen English 1010 classes to participate in.

\section{Statement of the Problem}

The main goal of this paper is to answer two main questions. First, is there a significant difference in LOOP assessment scores for ELL students and non-ELL students? It is

${ }^{*}$ Frans Albarillo is Assistant Professor/Reference \& Instruction Librarian at Brooklyn College; e-mail: falbarillo@brooklyn.cuny.edu. (C2017 Frans Albarillo, Attribution-NonCommercial (http://creativecommons.org/licenses/by-nc/4.0/) CC BY-NC. 
important to know if ELL students score higher or lower than students who are not ELLs to assess what kinds of difficulties ELL students are having with learning the content from the LOOP. Second, do ELL students indicate that the library information they are learning about via the LOOP is useful when compared to their non-ELL counterparts? Knowing how relevant the LOOP information is for ELL students gives the LOOP designers a measure of how the tutorial conveys useful information about library services to ELL students. For this study, the author uses reported home language and participation in high school ESL classes as a proxy in identifying the English language learner population. The author will further elaborate on operationalizing these research questions in the methodology section.

In considering the population, this article reviews the various and evolving definitions of ELLs and applies these definitions to a library setting. The definitions of ELLs are not always clear either in research or in practice. Librarians who begin researching the term will find that ELL is an umbrella term that not only includes ESL students and language minority students (the two specific populations that are identified in this study), but also includes other groups like non-native English speakers, international students, and generation 1.5 students. Are these terms interchangeable? What disciplines do they come from, and how are we to translate them into our field? In analyzing the data and defining the population for this study, the author conducted a selective literature review that focused on integrating ideas from various academic disciplines including applied linguistics, educational sociology, and library science.

These research questions are important in designing libraries' online information assessments for foreign-born populations, many of whom are ELLs. If there is a statistical difference in how English language learners score on assessments compared to non-ELL students, we have to look carefully at the modes of delivery in designing information literacy assessments for students with special language needs. The author hopes that the evidence gathered here will lead to improvements in the online tutorial's effectiveness with the ELL population at Brooklyn College. Additionally, the author hopes that, by selectively reviewing the literature of ELL definitions and working out how to define ELLs statistically, this study of ELLs will help other library and information professionals design assessments that track ELL performance.

\section{Institutional Background}

Brooklyn College, a public liberal arts undergraduate institution, is part of the City University of New York (CUNY) system. There are twenty-four institutions in the CUNY system. Brooklyn College has a full-time equivalent of 13,000 students, consisting of 11,000 undergraduates and 2,000 graduate students. ${ }^{1}$ The students are diverse, representing 150 countries and 105 languages. ${ }^{2}$ The Brooklyn College Library contains 1.5 million volumes, 45,000 serials, 43,000 electronic serials, and 40,000 electronic books. ${ }^{3}$ To provide a library orientation to incoming freshmen, the library at Brooklyn College developed the Library Online Orientation Program (LOOP) to disseminate information about the wide range of library services and resources available at the library.

At this large, public, minority-serving urban liberal arts college, working with ELLs is an important aspect of daily librarianship. Librarians serving ELLs in their institutions will recognize the importance in developing approaches, such as those detailed in this paper, that analyze assessment data to track meaningful and practical data about ELLs, in light of the complexity of language and cultural backgrounds the term connotes. To identify the ELL population for this study, the author used two simple questions to track ESL and language minority students in the LOOP assessment. Before we launch into that analysis, it is important to discuss the source 
of the data for this paper.

\section{A History of the Library Online Orientation Program (LOOP)}

This section introduces the Library Online Orientation Program (LOOP), which consists of a LOOP tutorial and the LOOP quiz, and is meant to give the reader a better understanding of data the author uses in this paper. According to Georgas, "The Brooklyn College Library's Reference Unit developed the Library's Online Orientation Program (LOOP) to provide freshman students with an entirely online, independent, flexible, and self-paced introduction to the library's resources and services." ${ }^{4}$ Decreasing librarians' heavy instruction load with regard to English 1010 classes was the primary motivation for creating the LOOP:

Until the spring 2009 semester, the college's reference librarians taught required one-shot English 1010 library orientation sessions for 600-1,300 students each semester (between twenty and fifty sections). These general introductions to the library's resources and services were both essential and time-consuming. To alleviate the time constraints that the English 1010 library sessions imposed upon them, the Brooklyn College Library's Reference Unit decided it was necessary to develop and implement an alternative, scalable, and entirely web-based model for English 1010 library instruction. ${ }^{5}$

The tutorial content was based on information literacy standards developed at CUNY, which were adapted from ACRL's information literacy standards:

The CUNY Library Information Literacy Advisory Committee (LILAC) compiled a set of Information Literacy Learning Goals and Objectives for all students who have completed 60 college credits; the University Librarian and Council of Chief Librarians approved these goals in the fall of 2007. These goals and objectives were adapted from the Association of College and Research Libraries (ACRL) Information Literacy Competency Standards for Higher Education and were streamlined for local use. ${ }^{6}$

These learning goals, combined with the local library curriculum taught by Brooklyn College librarians, were integrated to create the LOOP. The reader should note that the LOOP quiz was created before the LOOP tutorial to test the effectiveness of the library instruction using a pre-/post-test research design with the library instruction as the intervention. Regalado and Smale noted positive results from the initial pilot project: "Most student scores improved between the pre and post-quiz (Figure 4), suggesting that the majority of students did fulfill the research skills learning outcomes for the English 2 library instruction session. ${ }^{\prime 7}$ Regalado and Smale describe the initial development of the assessment quiz on the Blackboard course management software:

Blackboard did not allow us to randomize questions in the preferred fashion. We wrote four versions of each topic-specific question and wanted each quiz to consist of randomly generated questions that preserved the progression of categories and topics. The categories and topics approximate the process of doing research, and we intended for students to progress through them sequentially as they took the quiz. While Blackboard does allow for randomly generated quizzes, the control is not granular enough to enable randomization at the category or question level. Thus, we created four separate versions of the quiz, and assigned 
each student a different version for the pre-quiz and post-quiz. ${ }^{8}$

These original four quizzes, with some changes, would eventually become the LOOP quiz. Next, the online tutorial was built around the quiz content areas. Eventually the LOOP quiz was transferred to Sakai, another course management system, because at the time Blackboard could not export individual quiz scores, which represented important data for librarians to collect. ${ }^{9}$ According to Georgas, who took over the LOOP project, the first phase of the LOOP tutorial was launched in spring 2009. ${ }^{10}$ Georgas reports the following completion and success rates of the LOOP for three semesters-fall 2009, spring 2010, and fall 2010:

- Fall 2009, 60.9\% completion rate with an average score of $88 \%$

- Spring 2010, $60.9 \%$ completion rate with an average score of $90 \%$

- $\quad$ Fall 2010, 84.6\% completion rate with an average score of $90 \%{ }^{11}$

Georgas's article focuses on the library outreach component, specifically working with the English department to ensure the success of the LOOP as an orientation tool. This study includes an analysis of LOOP quiz results, using inferential statistics, as a source of data for assessing the effectiveness of online instruction on ELLs at Brooklyn College.

Undoubtedly, the LOOP designers had English language learners in mind during the entire design phase: "A majority of Brooklyn College students are first-generation college attendees. Although many students are native New Yorkers, English may not be their first or primary language of communication, given that students at the college speak ninety-five different languages."12 Online content for the tutorial was expertly edited over time for clarity. The collaboration between the library and the English department is ongoing, and all in-person library instruction for English 1010 classes has been replaced with the online tutorial for all freshman orientations. ${ }^{13}$

\section{LOOP Design}

There are two parts to the LOOP. The first part is the online tutorial, which can be viewed at https://library.brooklyn.cuny.edu/resources/loop/loop.php. Freshmen can also access the LOOP via the library's website at https://ibrary.brooklyn.cuny.edu/. The second component is the LOOP quiz, which can be accessed via a link at the bottom of the LOOP tutorial. The data for this study are drawn from the LOOP quiz assessment.

The LOOP "allow[s] for multiple submissions so that students [can] take the quiz as many times as they needed in order to pass it."14 The data analyzed in this paper includes the multiple submissions. This "open book" quiz design includes questions that are "multiple choice, true/false, fill in the blank, and matching." ${ }^{15}$ To allow the student to retake the LOOP quiz as many times as needed to earn a passing grade, the designers of the LOOP randomized the questions with the intention of forcing test retakers to take different versions of the quiz, reinforcing the variety of content related to information literacy and library services. The quiz has twenty-eight questions and requires a passing score of 70 percent. ${ }^{16}$ "The LOOP quiz questions add up to a total point value of eighty-seven, with a passing grade designated as sixty-one points (70 percent)." ${ }^{17}$ Students who do poorly on the LOOP quiz can retake the quiz until they receive a passing score of 70 percent. For further reading on the design and implementation of the LOOP, the author encourages librarians to read Regalado and Smale's article, ${ }^{18}$ which covers the initial development, design, and implementation of the LOOP as a pilot project. Georgas's article provides details on the different phases beyond the pilot, reporting on the progression of the LOOP between 2009 and 2010, and talks in detail on the collaboration with the English department and the responses from students taking the LOOP. This paper clearly benefits from the previous two articles' 
detailed documentation of LOOP's design, which gave the author a clear understanding of the kinds of questions that the LOOP data can answer. Because the LOOP is constantly in development, findings from this study and suggestions for changes in the design will be discussed in a later section, "Improving the LOOP for ELLs." These suggestions will focus on making the LOOP better designed for ELLs and modifying the quiz to gather better data on ELLs.

For this study, the author ran an analysis of LOOP quiz scores, using the answers to biographical questions on home language use and ESL participation to group the populations. ${ }^{19}$ In addition to the grouping variables, the author used answers to one 5-point Likert-type question relating to the perceived usefulness of the LOOP. ${ }^{20}$ The relevant questions are listed below, and the entire LOOP quiz is provided in the appendix. Not all of the quiz's biographical questions were useful-for example, question 3 (see the appendix) was poorly formed (students who attended more than two years, but less than three, have no response option, for example). The author immediately recognized the value of questions 1 and 2 as a way of identifying two populations in the data, language minority students and ESL students, which both fall into the ELL category. The LOOP quiz biographical and evaluation questions that were used in this study are:

1. What is your primary language at home? A. English B. A different language

2. Did you attend English as a Second Language (ESL) classes in high school? A. Yes, I attended ESL classes in high school. B. No, I did NOT attend ESL classes in high school.

28. On a scale of 1-5 ( 1 = not very helpful, 5 = very helpful $)$, how helpful was the LOOP Orientation in orienting you to the library's resources?

Questions 1, 2, and 28, as well as the final LOOP quiz score, provided the basis of the analysis in this paper.

These data were collected over four years and are available on Sakai, which is where the author accessed the data to export for the analysis. Now that the reader is familiar with the source of the data, as well as the instructional and curricular contexts behind the LOOP, this article continues with a selected review of the literature.

\section{Literature Review}

There are two sections to this selective literature review. The first section reviews definitions of English language learners from a number of disciplines including applied linguistics, educational sociology, and library and information science. The second section examines international students and librarianship in more detail, establishing clear definitions and exploring their disciplinary origins to help librarians understand the assumptions behind the population studied in this paper, navigate the complexity behind the term "English language learners," and see how other disciplines and researcher practitioners have approached the label.

\section{The Different Kinds of English Language Learners}

There are many labels that can be used for learners of English as a second language. After searching through several databases in library and information science, education, applied linguistics, and sociology, the author has found considerable variability in the term as reported by other researchers. For this review, the author performed citation searches on Google Scholar to identify highly cited scholarly works on ELLs. The author also looked at more recent works in highly regarded journals in the field of library and information science. In the field of LIS, a recent article by $\mathrm{Kim}^{21}$ on 48 ELL high school students performs a selective review of ELLs. Kim's review observes that the context for ELLs is broadly defined as linguistically and culturally diverse students: 
ELL students' information-seeking behavior has been actively studied in college settings, rather than at the elementary and secondary levels, in an effort to recognize the needs of linguistically and culturally diverse students and eventually to improve library and academic support for their research. Relevant studies show that the term international students is more frequently used than ELLs at the college level. These studies considered language barriers, cultural differences, lack of awareness of the research process, lack of knowledge on ethical issues, and unfamiliarity with library services as major obstacles to international students in their research process. ${ }^{22}$

Kim notes that international students are the focus of most studies of ELLs at the college level. Like Kim, the author had problems identifying studies of ELLs that were not focused on international students in the field of LIS. While international students can be a kind of English language learner, they differ greatly from other ELLs in two significant ways: first, international students often have a higher socioeconomic status than typical ELLs (like children of immigrants, for example), since obtaining an overseas student visa and paying international student tuition takes considerable economic resources. Second, international students will often have significant literacy in their non-English language (if they come from a non-English-speaking country) so that they are learning English as a foreign language, not English as a second language.

If we contrast this with the ability of ELLs, including language minority students and children of immigrants, we see ELLs' research and academic work in their first language is often limited due to interrupted schooling or little exposure to the academic varieties of their mother tongue, as pointed out ${ }^{23}$ by Donna Christian. Christian is at the Center for Applied Linguistics and has written an introduction to a systematic review in Educating English Language Learners. ${ }^{24}$ She notes that the terminology can be problematic in synthesizing the research literature because there is so much variation between practitioners and researchers when reporting on ELLs. For example, terms like "non-native English speaker, language minority student, ESL student, or bilingual student" have all been reported in the literature to also mean ELL. ${ }^{25}$ There are also legal terms such as "limited English proficient" (LEP) that can be found in the No Child Left Behind Act. ${ }^{26}$ LEP has negative connotations because the term suggests that individuals are deficient because they do not speak English, and Garcia prefers the term "emergent bilingual." 27

In the field of education, Li and Wang report that "there are no standard operational ways to identify ELLs. Most states and school districts use home language surveys and a variety of formal and informal assessments to identify the learners including teacher observation and interviews, and parent information forms, student records, student grades, informal and formal assessment, and referrals." ${ }^{28}$ Within education, ELL seems to be very actively used in $\mathrm{K}-12$ education ${ }^{29}$ but less so at the college level. The National Council of Teachers of English's Policy Brief highlights that the terminology is similarly confusing to English teachers. "The terms used to describe ELLs blur, overlap, and change with time, as well as with shifting socio-political dynamics." ${ }^{30}$ These key terms include ELL, ESL (English as a second language), LEP (limited English proficiency), EFL (English as a foreign language), and generation 1.5 students.

The formal definition of generation 1.5 students is that these are foreign-born students who came to the United States in their teens. These students were first identified by sociologists Ruben Rumbaut and Kenji Ima. ${ }^{31}$ Generation 1.5 students, depending on when they migrate to the United States, can benefit from ESL instruction at the high school and college levels. The data in this study probably contain some generation 1.5 students; however, there is no way to statistically tease them out of the population. 
Generation 1.5 students are often the first in their family to seek a college education. These characteristics, and their immigration status, make this population distinct from other kinds of ELLs. There have been some studies in the library literature focusing on generation 1.5 students as an ELL population. For example, looking at generation 1.5 Latino students, Catharine Harras and Edward Lopez analyze the information literacy history of Latino freshmen in California State University, Los Angeles. Harras and Lopez did not find any significant differences in college library use between students who spoke another language at home and students who spoke English at home. ${ }^{32}$ In this study, I examine this same variable, reported language use at home, though I show that it does make a difference in LOOP assessment scores for Brooklyn College students. Other generation 1.5 studies include those by Asher and Case ${ }^{33}$ and Asher, Case, and Zhong. ${ }^{34}$ Most studies rely on self-identifying as a generation 1.5 student, and in the section on "Improving the LOOP for ELLs" I provide suggestions for statistically defining this population.

Probably the broadest and most-cited definition of English language learners is given by the National Literacy Panel on Language-Minority Children and Youth. To define English language learners, the panel contrasts them with other groups like languageminority and second-language learners:

The most commonly used term, language minority refers to individuals from homes where language other than a society language [the dominant language] is actively used, who therefore have had an opportunity to develop some level of proficiency in a language other than societal language. A language-minority student may be of limited second-language proficiency, bilingual, or essentially monolingual in the second language (August \& Hakuta, 1997). Individuals who come from language backgrounds other than a societal language and whose second language proficiency is not yet developed to the point where they can profit fully from instruction solely in the second language are called second language learners. In instances where the students are acquiring English as a second language, they are referred to as English language learners. ${ }^{35}$

This definition is very strong because it clearly outlines the relationships between a language-minority student and an English language learner so that not all languageminority students are English language learners, while you must be a language-minority student to be an English language learner. For this paper, and with a general eye toward librarianship in practice, the author uses the definition of ELL used by the National Literacy Panel on Language-Minority Children and Youth - students who are acquiring English as a second language - and their definition will be the definition applied in the methodology and discussion sections in this paper. Furthermore, this paper uses the same convention as the National Council of Teachers of English in their Policy Brief in seeing ELL as a blanket term for ESL, LEP, EFL, generation 1.5 students, and students who are children of immigrants.

For librarians working with immigrant students, especially those who are recent high school graduates, the seminal book Children of Immigration by sociologists SuárezOrozco and Suárez-Orozco is a great point of departure for understanding ELLs who are the children of immigrants. In spite of the wide variation in the experiences, linguistic, and cultural backgrounds of these ELLs, Suárez-Orozco and Suárez-Orozco are able to draw some very helpful conceptual distinctions: "[w] e refer to 'immigrant children,' we strictly mean foreign-born children who have migrated, not the U.S.-born second generation. 'Children of immigrants,' on the other hand, refers to both U.S.-born and foreign-born children. While the experience of U.S.-born and foreign-born children 
differ in many respects (most importantly, all U.S.-born children are citizens), they nevertheless share an important common denominator: immigrant parents." ${ }^{36}$ Issues related to the immigrant household, citizenship, and immigration status are important factors to be sensitive to when engaging ELLs in information literacy instruction. Immigration status affects things like access to scholarships and in-state tuition, which are a part of the experiences of some English language learners. Immigrant households often produce first-generation college students whose parents may not be familiar with the language, bureaucracy, and costs associated with earning an undergraduate degree.

In addition to being aware of the context behind immigration patterns for ELLs, serving ELLs in academic libraries requires librarians to be familiar with the dynamic terminology around ELLs in education when creating programs and services. There is a strong tradition of research and partnerships between libraries and those working with ELL students and programs.

\section{Librarianship, ELLs, and International Students}

In this next section, it is important to keep in mind the definition provided by the National Literacy Panel on Language-Minority Children and Youth: "In instances where the students are acquiring English as a second language, they are referred to as English language learners." This paper, in accordance with this definition, uses the term ELL and ESL in very specific ways. In librarianship, ELL students are often called ESL students because they come into the library through ESL programs, while the literature using the term "ELL" generally occurs in K-12 settings. However, the author uses ELL in the title and this study because the population analyzed in this study are still English language learners but may all not be enrolled in an ESL programs or classes-hence, the umbrella term "ELL" was chosen.

ESL is the term used to report on ELLs in higher education for students enrolled in an ESL program. ESL students require a different pedagogy that focuses on vocabulary and sensitivity to other cultures. One of the main difficulties for ESL students is the language barrier. An article by Claire Walker and Amanda Click stresses the importance of overcoming the language barrier by teaching students about keyword searching and controlled vocabularies: "picking appropriate keywords and using controlled vocabulary are skills that must be learned, and these skills become even more difficult to develop for ESL students. ${ }^{137}$ Building academic research vocabulary and confidence in searching is at the center of working with ESLs. Walker and Click also highlight the importance of learning about the students' culture. ${ }^{38}$ Even simple cultural training is useful. One area where cultural understanding can improve student success is if librarians can identify whether or not a particular culture places a lot of importance on memorization and recitation, which are considered academic skills in many parts of the world. These students will need to be introduced to the cultural notion of plagiarism in a thoughtful way that does not devalue the academic systems that have trained the students.

Karen Bordonaro's timely analysis of the new ACRL framework, "Scholarship as Conversation," argues this new conceptual frame is an excellent metaphor to use when teaching ESL students, who are focusing on reading, writing, and listening skills. ${ }^{39}$ It is important to note here that scholarship as conversation is very culturally specific to American and Western European academic research, especially in the formal aspects of how an academic paper is formatted, how ideas are attributed, peer review, and how results are communicated. Bordonaro's classroom activities focus on parsing many of these elements in a way that will work well for ELLs. ${ }^{40}$ Partnerships with ESL departments and international exchange programs are also widely discussed in the literature. Deidra Herring, a librarian at Ohio State University, reports on the results of her partnership with an ESL instructor using a course enhancement grant program. ${ }^{41}$ 
The essay data that she gathered and analyzed showed that her students benefited from material on plagiarism, peer-to-peer advising, forming search strategies, librarian consultation, and concept mapping tools. ${ }^{42}$ Hensley and Love describe an impressive model for outreach and instruction at University of Illinois in Urbana-Champaign that is grounded in staff development and steered by a library diversity committee charged with promoting inclusivity and cultural awareness. ${ }^{43}$ They promote an active approach to understanding student demographics with regard to cultural awareness.

At the core of most articles on international students and library use is the need to design services that facilitate their linguistic and cultural transition to North American academic culture. In a qualitative study of Chinese engineering students by Zhao and Mawhinney, the authors note that "Not only do international students face challenges due to linguistic and cultural differences, their previous learning and research experiences also contribute to difficulties they face in western academic learning environments." 44 Western academic learning environments include cultural practices such as the convention of citing sources. It is common to find articles reporting on the difficulties of teaching citations. According to Zhao and Mawhinney, Chinese students found it difficult "knowing when and how to cite." 45

The most comprehensive annotated bibliography of international students in libraries is one by Davis that reviews 181 articles starting with the 1970s and ending in the 2000 s. Her questions, written in 2007 , are still very relevant today:

Current literature brings up new questions about what international students expect from their American academic library and what kind of library skills they have (research or otherwise). Is the language barrier between the English-speaking librarian and the foreign-language patron really a large concern for the foreign student? Are the concepts of "open stacks" and "reference services" still murky? Do international students still need library instruction and programming created especially for them? Has the rise of social software created new challenges or removed many obstacles in their information seeking processes ${ }^{46}$

At the heart of this bibliographical interrogation is the language barrier, and the idea that international students and other ELLs undergo a cultural transition in learning how to use U.S. academic libraries and in understanding the U.S. research process. In a recent article by Ishimura and Bartlett, ${ }^{47}$ the authors identified several key areas of teaching challenges for librarians working with international students: differences in academic expectations, differences in academic library systems, and English proficiency. Ishimura and Bartlett also find that librarians in their survey prefer to turn to their professional associations for the kinds of training they need to work with international students. ${ }^{48}$ In general, the literature that covers international students and academic libraries is in clear agreement that international students face difficulties in their cultural and linguistic transition to U.S. libraries and academic culture. While there are many more articles on international students that show a wide range of responses, services, and programming, these examples were selected to demonstrate particular themes in the literature.

While most universities provide international student services, these services may not be appropriate for other ELL populations such as immigrant students and generation 1.5 students, who are most likely not learning English as a foreign language and who often do not have the economic and cultural resources available to international students. At the time this paper was written, the author found no such services in the literature focused specifically on helping immigrant students at the university level (for example, an office of immigrant student services). This study aims to contribute to filling that gap in the literature by giving librarians a clearer understanding of the 
various kinds of ELLs there are and how this population may be tracked in assessment data. Distinguishing between these different kinds of ELL populations in assessments will help librarians better understand their needs. Knowing that there are different kinds of English language learners, the following methodology section will explain how the performance of these different kinds of ELLs were tracked in the LOOP data set.

\section{Methodology and Design}

The study population consists of all Brooklyn College students enrolled in the firstyear English 1010 course during the eight semesters covered by the data, as they were all required to take the LOOP. English 1010 is the first English class that all incoming students are required to take. Between 600 and 1,300 students participate in the LOOP each semester, though, with fewer English 1010 classes in the spring, spring LOOP participation is lower. This data set contains 4,786 quiz scores, and represents eight semesters of English 1010 courses:

- $\quad$ Semester $1 \mathrm{~N}=280$

- Semester $2 \mathrm{~N}=612$

- Semester $3 \mathrm{~N}=241$

- $\quad$ Semester $4 \mathrm{~N}=855$

- $\quad$ Semester $5 \mathrm{~N}=214$

- Semester $6 \mathrm{~N}=971$

- $\quad$ Semester $7 \mathrm{~N}=218$

- $\quad$ Semester $8 \mathrm{~N}=1,395$

Past analysis of the LOOP data did not include a separate analysis of ELLs. As described in the earlier article by Georgas, she analyzed three semesters of descriptive data in the form of completion rates and average scores. This current research design focuses on inferential statistical analysis and how to statistically operationalize the ELL population to determine how this population performs in the LOOP assessment and rates the usefulness of the LOOP tutorial. Using SPSS 21, a statistical analysis software, the author analyzed data from eight semesters, or four years, of LOOP quiz scores. The LOOP quiz is currently implemented on Sakai, an online content management system where the scores and responses are kept and previous semesters' responses are accessible. To work with and publish an analysis of the data, the author submitted an IRB application for IRB archival data use, which was approved, with exempt status, by the City University of New York. The author exported the data from Sakai to Microsoft Excel. Exact duplicate data was removed with Excel's duplicate values function. The author decided to keep multiple scores, in cases where a student took the quiz several times, so that the $\mathrm{N}$ represents the total number of times students took the LOOP quiz rather than the total number of students. Incomplete quiz responses were removed. The author anonymized the data and, afterward, imported and coded the data in SPSS 21.

The author started with several research questions concerning LOOP quiz results and perceived usefulness among different populations that can be studied in the data. The four populations are language-minority students (those who spoke a language other than English at home, according to their answer to question 1 of the LOOP quiz), English-only (EO) students (those who spoke English at home, according to their answer to question 1 of the LOOP quiz), ESL students (those who took ESL classes in high school, according to their answer to question 2 of the LOOP quiz), and non-ESL students (those who did not take ESL classes in high school, according to their answer to question 2 of the LOOP quiz). The author considered the language-minority students and the ESL students, together, as comprising the ELL population. The four specific research questions for this data set were: 
- $\quad \mathrm{R}^{1}$ Is there a statistical difference in the mean final LOOP quiz score between students who reported taking ESL courses in high school and students who did not report taking ESL classes in high school?

- $\quad \mathrm{R}^{2}$ Is there a statistical difference in the mean final LOOP quiz score between students who reported speaking a language besides English at home and students who reported that they only spoke English at home?

- $\quad \mathrm{R}^{3}$ Is there a statistical difference in the perceived usefulness of the LOOP tutorial between students who reported taking ESL courses in high school and students who did not report taking ESL classes in high school?

- $\quad \mathrm{R}^{4}$ Is there a statistical difference in the perceived usefulness of the LOOP tutorial between students who reported speaking a language besides English at home and students who reported that they only spoke English at home?

In the literature review, we saw that most ELLs face a language barrier, so there should be a statistically significant difference in their LOOP quiz scores when compared to those of non-ELL students. This is the rationale for asking $\mathrm{R}^{1}$ and $\mathrm{R}^{2}$. Similarly, related to the language barrier associated with ELLs, the content of the LOOP might not be that useful to ELLs if they experience problems in reading or comprehending the tutorial and quiz, since the tutorial and quiz contain a lot of text; hence the reason for posing $R^{3}$ and $R^{4}$. Knowing the answers to these questions, especially if there are large differences, will give library practitioners evidence to justify modifying the LOOP to better suit the ELL population.

The author exported the following question data (questions 1 and 2 of the LOOP quiz) into SPSS as a nominal binary grouping variable using the following codes:

Did you attend English as a Second Language (ESL) classes in high school?

A. Yes, I attended ESL classes in high school. (coded as 1 in SPSS)

B. No, I did NOT attend ESL classes in high school. (coded as 0 in SPSS)

What is your primary language at home?

A. English (coded as 0 in SPSS)

B. A different language (coded as 1 in SPSS)

Each student's final score for the LOOP quiz was coded as a continuous scale variable. Students could score from 0 to 87 .

The following question (question 28 of the LOOP quiz) was coded as an ordinal variable from 1 to 5 :

On a scale of $1-5$ ( 1 = not very helpful, 5 = very helpful $)$, how helpful was the LOOP Orientation in orienting you to the library's resources?

\section{Independent Samples T-Test}

To test the statistic differences between means of two independent groups in $R^{1}, R^{2}, R^{3}$, and $\mathrm{R}^{4}$, the author chose an independent samples T-test and made sure that the data agreed with the following assumptions: ${ }^{49}$

- Dependent variable is continuous

- Independent variables are categorical

- Sample is random and greater than 50

- Samples are independent

Table 1 shows the descriptive statistics of the four independent samples T-tests.

Table 2 shows the results of the output for the four independent samples T-tests. 


\begin{tabular}{|c|c|c|c|c|c|c|}
\hline \multicolumn{7}{|c|}{$\begin{array}{c}\text { TABLE } 1 \\
\text { Summary Statistics for Independent Samples T-Tests }\end{array}$} \\
\hline $\begin{array}{l}\text { Dependent } \\
\text { Variable }\end{array}$ & $\begin{array}{l}\text { Binary } \\
\text { Explanatory } \\
\text { Variable }\end{array}$ & Responses $(1,0)$ & $\mathbf{N}$ & Mean & $\begin{array}{l}\text { Std. } \\
\text { Deviation }\end{array}$ & $\begin{array}{l}\text { Std. } \\
\text { Error } \\
\text { Mean }\end{array}$ \\
\hline \multirow{4}{*}{$\begin{array}{l}\text { LOOP } \\
\text { Usefulness } \\
\text { (Scale } \\
\text { Variable) }\end{array}$} & \multirow[t]{2}{*}{$\begin{array}{l}\text { ESL } \\
\text { Participation }\end{array}$} & $\begin{array}{l}\text { Yes, I attended ESL } \\
\text { classes in high school }\end{array}$ & 510 & 4.28 & 0.988 & 0.044 \\
\hline & & $\begin{array}{l}\text { No, I did not attend ESL } \\
\text { classes in high school }\end{array}$ & 4,275 & 4.15 & 1.023 & 0.016 \\
\hline & \multirow{2}{*}{$\begin{array}{l}\text { Home } \\
\text { Language }\end{array}$} & A different language & 1,869 & 4.26 & 0.969 & 0.022 \\
\hline & & English & 2,917 & 4.10 & 1.047 & 0.019 \\
\hline \multirow{4}{*}{$\begin{array}{l}\text { LOOP Score } \\
\text { (Interval } \\
\text { Ratio } \\
\text { Variable) }\end{array}$} & \multirow[t]{2}{*}{$\begin{array}{l}\text { ESL } \\
\text { Participation }\end{array}$} & $\begin{array}{l}\text { Yes, I attended ESL } \\
\text { classes in high school }\end{array}$ & 510 & 82.17 & 12.819 & .568 \\
\hline & & $\begin{array}{l}\text { No, I did not attend ESL } \\
\text { classes in high school }\end{array}$ & 4,276 & 85.88 & 10.081 & .154 \\
\hline & \multirow{2}{*}{$\begin{array}{l}\text { Home } \\
\text { Language }\end{array}$} & A different language & 1,869 & 84.63 & 10.655 & .191 \\
\hline & & English & 2,917 & 86.02 & 10.312 & .246 \\
\hline
\end{tabular}

\section{Limitations}

There are many limitations in these data that can confound the validity of these results. There is no way to control for the variation in the quality of high school ESL instruction. (For a comprehensive list of programs, the author refers readers to Christian's systematic review on the kinds of ELL programs. ${ }^{50}$ ) Additionally, this data set does not include background demographics such as age, gender, socioeconomic status, or GPA, which are variables that can undoubtedly affect LOOP performance. Since the LOOP is an assessment of an online tutorial, it was not designed to gather these demographic data. Furthermore, because of the LOOP's design, the same student may have taken the quiz twice, which means that both quiz scores would be included. With these limitations in mind, the author used an independent samples T-test to compare differences in LOOP quiz scores and student attitudes to the LOOP tutorial.

\section{Discussion of Findings}

Table 1 shows the descriptive statistics. There are 510 respondents who report that they attended ESL classes in high school, and 4,275 respondents who report that they did not take high school ESL classes. As 510 is 10.6 percent of 4,786, the ESL population was a small percentage of the total population in the study. Language-minority students were a larger population, 39 percent $(1,869)$ of the total, with the rest 61 percent $(2,916 \mathrm{EOs})$. Looking at these data, the author sees that not all language-minority students have taken ESL classes, which indicates that these students might have not been properly placed into ESL classes or they might be fluent bilinguals, but there is no way to know for this data set.

There are very small differences in the mean column. In actual mean scores, ESL students scored 82.17 (out of 87 , with 61 or $70 \%$ as the minimum passing score), slightly lower than non-ESL students, who scored 85.88 . The mean score of language-minority students was 84.63, compared to EOs at 86.02. With regard to the usefulness of the LOOP, ESL and non-ESL students gave the LOOP a usefulness rank of 4.28 and 4.15, respectively, with a mean above 4 (useful) out of 5 on the Likert scale. Languageminority students ranked the LOOP as more useful than EO students, giving the LOOP 


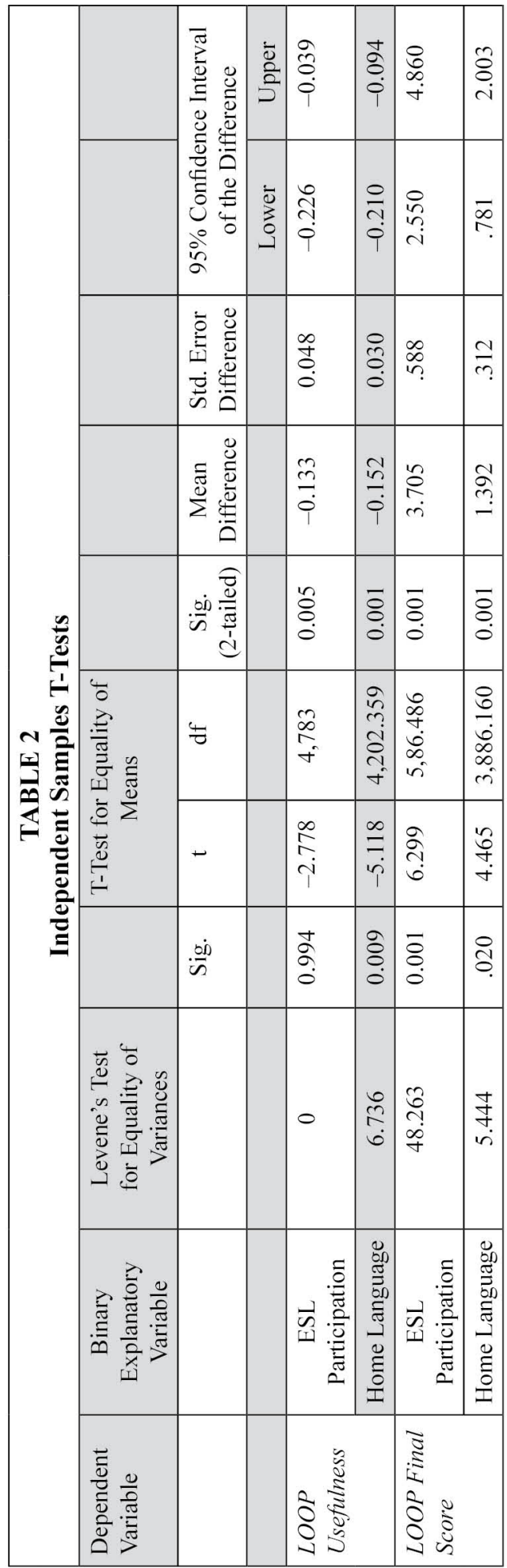

a mean ranking of 4.26 , while the $\mathrm{EO}$ mean was 4.10. These data show that, overall, ELLs students scored slightly lower than their non-ELL counterparts and that ELLs, on the average, found the LOOP more useful than their nonELL colleagues.

Table 2 shows the findings of the four independent samples T-tests results from SPSS. The P value in the Sig. (2-tailed) column shows us that there are very small $P$ values (<.001), meaning there are statistical differences between ESL students and non-ESL students, as well as between language-minority students and EOs. On closer inspection, the difference in the mean final LOOP quiz score between ESL and non-ESL students is small, with ESL students scoring on the average 3.705 points less than non-ESL students.

The results are similar for languageminority students. Table 2 shows that the $P<.001$, meaning that there is a statistical finding in the mean final LOOP quiz score between students who reported speaking a language besides English at home and students who reported that they only spoke English at home. The difference in mean quiz scores is very small, with language-minority students scoring, on the average, 1.392 points less than EO students.

There is a statistical difference, $P<.001$, in the perceived usefulness of the LOOP tutorial between students who reported taking ESL courses in high school and students who did not report taking ESL classes in high school. Likewise, the mean difference is very small and probably not substantive. Table 1 shows the mean difference as rating for 4.28 for ESL students and 4.15 for non-ESL students, out of a 5 -point scale $(5=$ very helpful, $4=$ helpful, $3=$ neutral, $2=$ not helpful, 1 = not very helpful). Table 2 also shows that there is a statistical difference, $P<.001$, in the perceived usefulness of the LOOP tutorial be- 
tween language minority and EOs. As we see in table 2, the mean difference is small at -0.152 . EOs, on the average, gave the LOOP a rank of 4.10 , while language-minority students ranked the LOOP a little higher at 4.26. Both groups found the LOOP helpful.

\begin{tabular}{|l|c|c|c|c|}
\hline \multicolumn{5}{|c|}{ TABLE 3 } \\
Summary of Research Questions \\
\hline $\begin{array}{l}\text { P Value for Independent Samples } \\
\text { T-Tests (P<.001) }\end{array}$ & $\begin{array}{c}\text { Mean LOOP } \\
\text { Quiz Score }\end{array}$ & $\begin{array}{c}\text { Mean } \\
\text { Difference }\end{array}$ & $\begin{array}{c}\text { Mean } \\
\text { Usefulness } \\
\text { Rank }\end{array}$ & $\begin{array}{c}\text { Mean } \\
\text { Difference }\end{array}$ \\
\cline { 1 - 4 } ESL (N=510) & 82.17 & $-3.71\left(\mathrm{R}^{1}\right)$ & 4.28 & \multirow{2}{*}{$0.13\left(\mathrm{R}^{2}\right)$} \\
\cline { 1 - 2 } Non-ESL (N=4,276) & 85.88 & & 4.15 & \\
\hline Language Minority $(\mathrm{N}=1,869)$ & 84.63 & $-1.39\left(\mathrm{R}^{3}\right)$ & 4.26 & \multirow{2}{*}{$0.16\left(\mathrm{R}^{4}\right)$} \\
\cline { 1 - 2 } English Only (N=2,917) & 86.02 & & 4.1 & \\
\hline
\end{tabular}

Table 3 shows the key statistics that help answer each research question posed in the methodology.

Table 3 shows us that, on the average, ESL students and language-minority students score 3.71 and 1.39 points less on the LOOP quiz than their respective non-ESL and EO counterparts. From these data we can conclude that ELLs, defined as ESL and language-minority students, score less than non-ELLs. This finding is consistent with the literature on the linguistic difficulties faced by English language learners. Table 3 shows us that, on the average, ESL students and language-minority students rank the LOOP tutorial .13 points and .16 points higher than non-ESL and EO students, respectively. This statistical finding supports the statement that ELLs find the LOOP tutorial more useful than non-ESL and EO students. These are small differences in final quiz scores between ELLs and non-ELLs, but later this paper will discuss how to improve the LOOP to minimize these differences. It is not surprising that a self-paced online tutorial would receive a higher ranking from ELLs, because this format allows students to learn the material at their own speeds.

\section{Improving the LOOP for ELLs}

Ways of improving the LOOP content could include using the same material but incorporating practices like presenting information with multiple modalities by using videos and images to complement text content. Another approach is following plain language recommendations by keeping the tutorial sentence structures simple, with predictable subject-object-verb word order, short paragraphs, and no complex vocabulary or jargon..$^{51}$ There is a measure is known as lexical complexity ${ }^{52}$ that could help librarians who want a quantitative measure of the comprehensibility of their assessments.

To create a deeper statistical analysis of the LOOP quiz, additional independent variables could be added such as:

- Gender

- Age

- Immigration status (U.S. citizen, permanent resident, naturalized citizen, DACA, international student with an F, J, M, A, H1B, or K visa, prefer not to disclose, other)

- $\quad$ Foreign-born status (Were you born outside the United States or its territories?)

$\square \quad$ Generation 1.5 status (If the answer is yes to foreign-born status, what year did you move to the United States?)

- Zip code 
Having these additional biographical questions would allow the use of regression techniques to see if other factors have a stronger effect on LOOP quiz scores.

In the data, I discarded one poorly formed question:

How long did you attend high school in the United States?

a. 1-2 years

b. 3-4 years

c. 4+ years

d. I did NOT attend high school in the United States

The responses to this question could be changed so that they are all mutually exclusive, making a valid scale variable. The new responses could be:

a. Less than 1 year

b. Between 1 and 2 years

c. 2 years

d. Between 2 and 3 years

e. 3 years

f. Between 3 and 4 years

g. 4 years

h. More than 4 years

i. I did NOT attend high school in the United States

These are just a few ways in which improvements to the LOOP tutorial and quiz could offer a more useful experience for students and provide librarians with a richer set of data. Furthermore, not only will the suggestions on presenting the information using multiple modalities and plain language help ELL populations understand the content in the tutorial, multiple modalities and writing using plain language guidelines will also make the LOOP a better tutorial for non-ELLs who have different learning styles.

\section{ACRL Diversity Standards}

In 2012, the Association of College and Research Libraries (ACRL) provided academic libraries with a framework for diversity and cultural competency through their 11 diversity standards..$^{53}$ Applying these standards as a conceptual framework for working with ELLs can give rise to a coordinated effort of research among librarians who are interested in creating and improving services to ELLs. ${ }^{54}$ This section reflects on ideas from the literature review and the findings of this paper and addresses each of the 11 standards.

Being aware of one's own cultural and linguistic practices (Standard 1) is very important so that librarians can be aware of the place of their cultural and linguistic practices in relation to other cultures. For example, monolingual English speakers might begin to investigate the variation of language by taking note of the varieties of regional Englishes. Raising one's awareness of variation in a language like English would help an individual understand the kinds of challenges ELLs face when encountering regional dialects of English. Cross-cultural knowledge (Standard 2) is particularly important with ELLs because these students come from a variety of language and cultural backgrounds and have a wide range of research and educational experiences. Researching the main cultures, countries of origin, and reasons for migration will help the librarian better understand the kinds of cultural expectations in addition to the academic and linguistic skills these students will be bringing to the library. Developing organizational and professional values (Standard 3) is important because having cultural sensitivity and maintaining an inclusive library is a skill that must be acquired through meaningful dialogue and research. How do you help ELLs who are refugees or immigrants or who may have strong religious concerns over a particular research topic? How do you help individuals from cultures where there is a strong collective identity find original or "valid" research topics? The steps to answering these questions can be a dialogue 
or process where a librarian can consult with colleagues and feel empowered to seek resources to understand a variety of cultural perspectives. The key to intercultural communication is never to assume that one's own idea of normal is the societal norm for a person who comes from a different society.

In the literature review, the author showed that librarianship has had a strong history of developing collections, programs, and services (Standard 4) for international students, but how about for other ELLs? In developing programs for other ELLs such as language minority students or ESL students, the author advocates an evidence-based librarianship approach. This article included some actionable data on ELLs, and, with the help of conceptual tools like the ACRL Diversity Standards, librarians can identify gaps in library services and student skills. Librarians working with ELLs should investigate and be able to refer ELLs to the kinds of services that these students need, whether it be a referral to International Student Services or something else. At the City University of New York there are free immigration services that provide multilingual assistance to students who have questions about "Deferred Action for Childhood Arrivals (DACA); Relative Petitions; Adjustment of Status; Consular Processing; Certificates of Citizenship; Replacement of Lost/Damaged Immigration Documents; and Diversity Lottery entries." ${ }^{55}$ With regard to service delivery (Standard 5), the Brooklyn College Library is a place where students can find reliable information and referrals related to academics, including administrative processes. Librarians at the reference desk often help students navigate the admissions and registration polices, which may be alien to first-generation college students. In reference interviews, librarians also direct these students to other campus services for further support.

Because ELLs have different language backgrounds, acknowledging language diversity (Standard 6) by being inclusive of accents and speaking ability is an important part of working with this population. Focusing on meaning-driven language interactions (worrying about what the student is trying to say versus how the student is saying it) is very important when working with students for whom English is not their first language. Workforce diversity (Standard 7) includes "obtaining statistics on the diversity of students, staff, and librarians." 56 This article includes survey questions that librarians can include in their assessments that will allow them to statistically tease out ELLs in assessment data. Organization dynamics (Standard 8) can include bringing in ELL experts or partnering with ESL departments to help librarians create better services for ELLs. There are many examples of these partnerships in the literature review. Staff members and librarians who are bicultural or who have lived for a significant period of time outside their own culture can be identified as potential resources for crosscultural leadership (Standard 9).

As the demographics of the undergraduate population change, it is important to communicate with our library schools and associations to develop appropriate professional education and continuous learning opportunities (Standard 10) around designing services for ELLs and other diverse communities. Immigration is an important topic in both rural and urban areas. Being mindful of other ways of thinking and other countries' research standards (Standard 11) is very important when working with ELLs on culture-specific academic practices such as citations, as well as concepts like critical thinking and academic originality. In some countries, the ability to memorize and recite is seen as an academic skill, but it can become an academic liability in the United States if the student does not understand the purpose of citations.

\section{Conclusion}

Inferential statistical techniques can help improve the usability of an assessment by using demographic questions to parse out particular populations who may not be per- 
forming as well. In this paper, by examining assessment data and applying quantitative reasoning, the author was able to validate that ELLs were slightly underperforming, compared to non-ELLs, in their LOOP quiz. Additionally, ELLs found the LOOP more helpful than their non-ELL counterparts. The author has recommended several solutions to correct this small difference in performance, as well as a way to measure the effectiveness of these recommendations.

\section{Implications for Future Research}

There are additional data that can used to improve the usability of the LOOP. These could include analyzing the parts of the LOOP where students performed poorly, which is possible because final scores are recorded by section. Additionally, quantitative analysis is very limited in its ability to identify experiences and processes that students have with the LOOP. To corroborate some of the conclusions stated in this paper, further qualitative evidence such as interviews or focus groups could help identify areas that ELLs find difficult or confusing. Ideally, it would be good to use both quantitative and qualitative data to have a more holistic understanding of how one set of students' experiences with a tutorial may be different from that of another set of students. At the time of writing, the author is working on the results of a mixed methods study on foreign-born students, based in part on the analysis of this data set, which has allowed him to create a survey tool that looks at and compares the different kinds of ELLs (immigrant students, generation 1.5 students, and international students) and their library use, research habits, language use, and migration experiences.

\section{Acknowledgments}

The author would to acknowledge LuAnn Lupia, Mariana Regalado, Maura Smale, Carlos Cruz, and Helen Georgas for their help and expertise with the LOOP. The author would also like to thank the Institute for Research Design in Librarianship, especially Lili Luo, for the statistical advice. The author assumes responsibilities for any flaws and limitations. 


\section{APPENDIX. LOOP Quiz Questions}

\section{Part 1 of 25}

Question 1 of 28 (0 Points)

What is your primary language at home?

a. English

b. A different language

Question 2 of 28 (0 Points)

Did you attend English as a Second Language (ESL) classes in high school?

a. Yes, I attended ESL classes in high school.

b. No, I did NOT attend ESL classes in high school.

Question 3 of 28 (0 Points)

How long did you attend high school in the United States?
a. 1-2 Years
b. 3-4 Years
c. 4+ years
d. I did NOT attend high school in the United States

Question 4 of 28 (0 Points)

When you do research, where do you usually start looking for information?
a. Library Reference Desk
b. Search engine (Yahoo!, Google, and the like)
c. Library databases
d. I haven't done any research yet
e. Library catalog
f. Other

\section{Part 2 of 25: Government Documents}

Question 5 of 28 (4.0 Points)

The Government Documents Center is where you can find ...
a. Help with locating information about government documents
b. Statistical information
c. Census information
d. All of the above

\section{Part 3 of 25: Group Study Rooms}

Question 6 of 28 (4.0 Points)

Group study rooms:
a. are only for seniors
b. can be reserved at the Circulation Desk
c. are for two students or more at a time
d. can be reserved online
e. B) and C)

\section{Part 4 of 25: New Media Center}

Question 7 of 28 (4.0 Points)

If you need a video, please visit:
a. the Circulation Desk
b. the New Media Center
c. the Reserve Room
d. the Reference Desk 


\section{Part 5 of 25: Reserve Room (True/False)}

Question 8 of 28 (4.0 Points)

Books on reserve can be used for 2 hours at a time in the library.

True

False

\section{Part 6 of 25: Special Collections}

Question 9 of 28 (4.0 Points)

Special Collections:
a. is open 9AM-9PM Monday through Thursday
b. is open on the weekends 10AM-6PM
c. is not open on Friday
d. is not open on the weekends

\section{Part 7 of 25: Study Carrels (True/False)}

Question 10 of 28 (4.0 Points)

Study carrels are ONLY located on the 1st floor of the library.

True

False

\section{Part 8 of 25: Videos \& DVDs (True/False)}

Question 11 of 28 (4.0 Points)

Students will be charged a late fee of $\$ 1.20$ per hour for 2-hour reserve loan items that are not returned on time.

True

False

\section{Part 9 of 25: Computing Labs}

Question 12 of 28 (4.0 Points)

Every student gets free printouts that can be used at any computer lab on campus.

True

False

\section{Part 10 of 25: Reference}

Question 13 of 28 (4.0 Points)

Students visit the reference desk:
a. to check out books
b. to get assistance with research papers
c. to get help using the catalog
d. both B) and C)

\section{Part 11 of 25: Plagiarism}

Question 14 of 28 (4.0 Points)

You do NOT have to cite an image created by another author.

True

False

\section{Part 12 of 25: Circulation}

Question 15 of 28 (4.0 Points)

Books:

a. are checked out at the Circulation Desk on the 1st floor

b. are checked out at the Reference Desk on the 1st floor 
c. have a 3-week loan period

d. are checked out at the New Media Center on the 2nd floor

e. both $\mathrm{A}$ ) and $\mathrm{C}$ )

\section{Part 13 of 25: Laptop Loan Program}

Question 16 of 28 (4.0 Points)

Students need to provide 2 forms of ID and sign the Laptop Loan Agreement to check out a laptop from the New Media Center.

True

False

\section{Part 14 of 25: Periodicals}

Question 17 of 28 (4.0 Points)

Electronic periodicals can only be accessed on campus.

True

False

\section{Part 15 of 25: Off-Campus Access}

Question 18 of 28 (4.0 Points)

To access the library's resources from off-campus you will need your Brooklyn College e-mail ID.

True

False

\section{Part 16 of 25: Copiers, Scanners, and Such}

Question 19 of 28 (4.0 Points)

Scanners are ONLY available on the 1st floor of the library.

True

False

\section{Part 17 of 25: Google and Wikipedia}

Question 20 of 28 (4.0 Points)

The library has many databases that contain free articles for students and faculty. These articles are often only accessible for a fee when you access them via Google.

True

False

\section{Part 18 of 25: Matching Questions}

Question 21 of 28 (3.0 Points)

According to the LOOP, where would you most likely complete the tasks below?

a. Circulation Desk

b. Reference Desk

c. Government Documents Center

1. Students visit this desk to get assistance with research papers

2. Students visit this desk to get assistance with statistical information

3. Students visit this desk when they want to reserve a Group Study Room

\section{Part 19 of 25: Books}

Question 22 of 28 (4.0 Points)

Students can search for a book in the library's catalog: 

a. by author's name
b. by title of work
c. by subject
d. by keyword
e. all of the above

\section{Part 20 of 25: Ask-A-Librarian}

Question 23 of 28 (4.0 Points)

Students will not be able to receive research assistance when the library is closed.

True

False

\section{Part 21 of 25: Reading Room}

Question 24 of 28 (4.0 Points)

The Christoph M. Kimmich Reading Room contains circulating books.

True

False

\section{Part 22 of 25: Articles}

Question 25 of 28 (4.0 Points)

Students have access to:

a. both popular and scholarly/peer-reviewed articles

b. scholarly/peer-reviewed articles only.

c. Students do not have access to articles at the Brooklyn College Library

d. popular articles only

\section{Part 23 of 25: Wireless Access}

Question 26 of 28 (4.0 Points)

Which student computer labs can you visit to get your wireless-ready device configured for wifi access?

a. Students can go to the student computer lab in Boylan Hall

b. Students can go to the student computer lab in the WEB building

c. Students can go to the student computer lab in Whitehead Hall

d. Students can go to the student computer labs in the library

\section{Part 24 of 25: Music Library}

Question 27 of 28 (4.0 Points)

Students can check out:

a. only 5 items at a time from the music library

b. an unlimited number of items from the music library

c. only 10 items at a time from the music library

d. only 1 item at a time from the music library

\section{Part 25 of 25: Orientation Question}

Question 28 of 28 (0.0 Points)

PLEASE NOTE: After you successfully submit your quiz for grading, make sure to do the following:

1. Print the "Gradebook" page that includes your score (70\% to pass)

2. Go to the Brooklyn College Library's Reference Desk (1st Floor) and have a librarian stamp the "Gradebook" page with your score 
3. Hand in the "Gradebook" page to your English 1010 instructor to receive credit for the Library Orientation program

On a scale of $1-5(1=$ not very helpful, 5 = very helpful $)$, how helpful was the LOOP Orientation in orienting you to the library's resources? Please provide feedback in the space below.

\section{Notes}

1. Brooklyn College, "Enrollment Snapshot 2014," Brooklyn College Fast Facts, available online at www.brooklyn.cuny.edu/web/about/facts.php [accessed 9 November 2015].

2. Brooklyn College, "Brooklyn College Fast Facts," Brooklyn College Fast Facts, available online at www.brooklyn.cuny.edu/web/about/facts.php [accessed 9 November 2015].

3. Ibid.

4. Helen Georgas, "The Implementation of an Independent and Self-Paced Online Library Orientation for Freshman Students and the Use of Sakai as a Quiz Management System (QMS)," College \& Undergraduate Libraries 21, no. 1 (Jan. 2014): 56, doi:10.1080/10691316.2014.877737.

5. Ibid., 57.

6. Maura A. Smale and Mariana Regalado, “Using Blackboard to Deliver Library Research Skills Assessment: A Case Study," Communications in Information Literacy 3, no. 2 (Sept. 2009): 147.

7. Ibid., 149.

8. Ibid., 152.

9. Georgas, "The Implementation of an Independent and Self-Paced Online Library Orientation," 64.

10. Ibid., 62.

11. Ibid., $67-68$.

12. Ibid., 57.

13. Ibid., 59.

14. Ibid., 57.

15. Ibid., 64.

16. Ibid., 65.

17. Ibid.

18. Smale and Regalado, "Using Blackboard to Deliver Library Research Skills Assessment."

19. Georgas, "The Implementation of an Independent and Self-Paced Online Library Orientation," 65.

20. Ibid., 68.

21. Sung Un Kim, "Exploring the Knowledge Development Process of English Language Learners at a High School: How Do English Language Proficiency and the Nature of Research Task Influence Student Learning?" Journal of the Association for Information Science and Technology 66, no. 1 (Jan. 1, 2015): 128-43, doi:10.1002/asi.23164.

22. Ibid., 130.

23. Donna Christian, "Introduction," in Educating English Language Learners: A Synthesis of Research Evidence (New York, N.Y.: Cambridge University Press, 2006), 2.

24. Fred Genesee and Cambridge University Press, Educating English Language Learners: A Synthesis of Research Evidence (New York, NY: Cambridge University Press, 2006).

25. Christian, "Introduction," 10.

26. Ibid., 11.

27. Ofelia Garcia, “Emergent Bilinguals and TESOL: What's in a Name?” TESOL Quarterly 43, no. 2 (2009): 322-26.

28. Guofang Li and Wenxia Wang, "61. English Language Learners," in 21st Century Education: A Reference Handbook, ed. Thomas L. Good, vol. 2 (Thousand Oaks, Calif.: SAGE Publications, 2008), 98, available online at http://go.galegroup.com/ps/i.do?id=GALE\%7CCX3074700082\&v=2.1 \&u=cuny_broo39667\&it=r\&p=GVRL\&sw=w\&asid=d61c5b53a9ed3bcc2193976e81d86f3a [accessed 11 November 2015].

29. NCTE's James R. Squire Office of Policy Research, “English Language Learners: An NCTE 
Policy Research Brief," NCTE Policy Briefs, available online at www.ncte.org/policy-research/briefs [accessed 21 April 2016].

30. Ibid., 2.

31. Ruben G. Rumbaut and Kenji Ima, "The Adaptation of Southeast Asian Refugee Youth: A Comparative Study. Final Report to the Office of Resettlement" (Jan. 1988), available online at http://eric.ed.gov/?id=ED299372 [accessed 11 November 2015].

32. Catherine Haras, Edward M. Lopez, and Kristine Ferry, "(Generation 1.5) Latino Students and the Library: A Case Study," Journal of Academic Librarianship 34, no. 5 (Sept. 2008): 430.

33. Curt Asher and Emerson Case, "A Generation in Transition: A Study of the Usage and Attitudes toward Public Libraries by Generation 1.5 Composition Students," Reference $\mathcal{E}$ User Services Quarterly 47, no. 3 (Spring 2008): 277.

34. Curt Asher, Emerson Case, and Ying Zhong, "Serving Generation 1.5: Academic Library Use and Students from Non-English-Speaking Households," College E Research Libraries 70, no. 3 (May 2009): 270-71.

35. National Literacy Panel on Language-Minority Children and Youth (U.S.), Diane August, and Timothy Shanahan, Developing Literacy in Second-Language Learners: Report of the National Literacy Panel on Language Minority Children and Youth (Mahwah, N.J.; Washington, D.C.: Lawrence Erlbaum Center for Applied Linguistics, 2006), 2.

36. Carola Suárez-Orozco and Marcelo M Suárez-Orozco, Children of Immigration (Cambridge, Mass.; London: Harvard University Press, 2002), 1.

37. Claire Walker and Amanda Click, "Meeting the Reference Expectations of ESL Students:

The Challenges of Culture," College \& Research Libraries News 72, no. 1 (Jan. 2011): 21.

38. Ibid., 22.

39. Karen Bordonaro, "Scholarship as a Conversation: A Metaphor for Librarian-ESL Instructor Collaboration," Collaborative Librarianship 7, no. 2 (Apr. 2015): 58.

40. Ibid., 60-62.

41. Deidra Herring, "A Purposeful Collaboration: Using a Library Course Enhancement Grant Program to Enrich ESL Instruction," Reference Librarian 55, no. 2 (Apr. 2014): 128-43.

42. Ibid., 135-36.

43. Emily Love and Merinda Kaye Hensley, A Multifaceted Model of Outreach and Instruction for International Students (Chicago: Association of College and Research Libraries, 2011).

44. Jennifer Congyan Zhao and Tara Mawhinney, "Comparison of Native Chinese-Speaking and Native English-Speaking Engineering Students' Information Literacy Challenges," Journal of Academic Librarianship 41, no. 6 (Nov. 2015): 714, doi:10.1016/j.acalib.2015.09.010.

45. Ibid., 722.

46. Kaetrena Davis, "Global Evolution: A Chronological Annotated Bibliography of International Students in U.S. Academic Libraries," University Library Faculty Publications (Jan. 1, 2007), 5, available online at http://scholarworks.gsu.edu/univ_lib_facpub/22 [accessed 11 November 2015].

47. Yusuke Ishimura and Joan Bartlett, "Are Librarians Equipped to Teach International Students? A Survey of Current Practices and Recommendations for Training," Journal of Academic Librarianship 40, no. 3/4 (May 2014): 313-21, doi:10.1016/j.acalib.2014.04.009.

48. Ibid., 320.

49. Chava Frankfort-Nachmias and Anna Leon-Guerrero, Social Statistics for a Diverse Society (Thousand Oaks, Calif.: SAGE Publications, 2015), 282-94.

50. Christian, "Introduction," 3-5.

51. Lawrence M. Solan, Peter M. Tiersma, and Mark Adler, "The Plain Language Movement," Plainlanguage.gov Improving Federal Communication to the Public, http://www.plainlanguage. gov/ [accessed 11 November 2015].

52. Xiaofei Lu and Haiyang Ai, "Syntactic Complexity in College-Level English Writing: Differences among Writers with Diverse L1 Backgrounds," Journal of Second Language Writing, 29 (Sept. 2015): 16-27, doi:10.1016/j.jslw.2015.06.003.

53. Association of College and Research Libraries, "Diversity Standards: Cultural Competency for Academic Libraries," 2012, available online at www.ala.org/acrl/standards/diversity [accessed 11 November 2015].

54. Davis, "Global Evolution," 5.

55. CUNY Citizenship Now, "CUNY Citizenship Now," available online at www1.cuny.edu/ sites/citizenship-now/ [accessed 25 April 2016].

56. Association of College and Research Libraries, "Diversity Standards." 